\title{
Clinical experience in treatment of diffuse unilateral subretinal neuroretinitis
}

\author{
This article was published in the following Dove Press journal: \\ Clinical Ophthalmology \\ 28 September 2015 \\ Number of times this article has been viewed
}

\author{
Nidhi Relhan ${ }^{1,2}$ \\ Avinash Pathengay ${ }^{2,3}$ \\ Vishal Raval ${ }^{2}$ \\ Sameera Nayak ${ }^{2}$ \\ Himadri Choudhury ${ }^{3}$ \\ Harry W Flynn Jr' \\ 'Department of Ophthalmology, \\ Bascom Palmer Eye Institute, \\ University of Miami Miller School \\ of Medicine, Miami, FL, USA; ${ }^{2} \mathrm{Kode}$ \\ Venkatadri Chowdry Campus, \\ Vijayawada, Andhra Pradesh, India; \\ ${ }^{3}$ Retina and Uveitis Services, LV \\ Prasad Eye Institute, GMR Varalakshmi \\ Campus, Visakhapatnam, Andhra \\ Pradesh, India
}

Purpose: To describe the clinical features, management, and outcomes of patients with diffuse unilateral subacute neuroretinitis (DUSN).

Methods: A noncomparative, consecutive analysis of case series from two tertiary care campuses of LV Prasad Eye Institute, India, between January 2011 and April 2014 was performed. Medical records of the patients presenting with DUSN (early or late stage) were reviewed.

Results: The current study included 13 patients. The majority $(10 / 13,76.92 \%)$ of the patients were aged 20 years or less. All patients had unilateral eye involvement. Visual acuity at presentation was $20 / 200$ or worse in $9 / 13(69.23 \%)$ patients. A delay in diagnosis occurred in $6 / 13$ patients, and initial diagnosis in these patients included retinitis pigmentosa (4 patients) and posterior uveitis ( 2 patients). Clinical features included early presentation (prominent vitritis, localized retinitis, and vasculitis) in 7/13 (53.85\%) patients and late presentation (attenuation of vessels, retinal pigment epithelium atrophic changes, and optic atrophy) in 6/13 (46.15\%) patients. Worm could not be identified in any of the cases. All the patients received laser photocoagulation of retina and oral albendazole treatment for a period of 30 days. With treatment, visual acuity improved in seven patients (six early stage, one late stage) and remained unchanged in six patients. Mean follow-up period was 8.69 months (range, 1-21 months). The mean central foveal thickness in the affected eye, done by optical coherence tomography, during the late stage of the disease was $188.20 \pm 40 \mu \mathrm{m}$ (range, 111-242 $\mu \mathrm{m}$ ), which was significantly thinner than the fellow eye, $238.70 \pm 36.90 \mu \mathrm{m}$ (range, $186-319 \mu \mathrm{m}$ ), $P=0.008$.

Conclusion: DUSN is a serious vision threatening disease, which may progress to profound vision loss in the later stage of the disease. Visualization of subretinal worm is usually not possible. Treatment with high-dose albendazole therapy and laser photocoagulation may alter the blood-retinal barrier and may be useful in achieving visual recovery.

Keywords: diffuse unilateral subacute neuroretinitis, retinitis pigmentosa, OCT, albendazole therapy, central macular thickness

\section{Introduction}

Diffuse unilateral subacute neuroretinitis (DUSN), also known as "unilateral wipe out syndrome", is a progressive ocular infectious disease caused by various species of nematodes, leading to inflammation and degeneration of the outer retina and the retinal pigment epithelium (RPE). ${ }^{1}$ Nematode infection of the eye was first reported in the year 1950 by Wilder ${ }^{2}$ in an enucleated eye specimen. In 1978, Gass et al $^{1}$ was the first to describe the clinical entity of DUSN after finding a worm in 2 out of 36 cases with such clinical findings. DUSN is a progressive inflammatory ocular pathology which is characterized by unilateral visual loss, vitreous cells, degenerative retinal pigmentary changes, optic disc and retinal vessel inflammation., ${ }^{1,3-5}$

Clinical presentation of DUSN is divided into two stages - early and late. ${ }^{1}$ In early stage, the patient is either asymptomatic or presents with acute onset of multiple and
Correspondence: Avinash Pathengay

Retina and Uveitis Services, LV Prasad Eye Institute, GMR Varalakshmi

Campus, II-II3/I, Hanumanthawaka Junction, Visakhapatnam 530 040,

Andhra Pradesh, India

Tel +9l 9989156789

Email avinash@lvpei.org 
rapidly changing, central/paracentral scotomata, photopsias, or unilateral vision loss. ${ }^{1,3-7}$ Anterior segment inflammation is uncommon in early stage, with a few exceptional case reports where keratic precipitates and a hypopyon have been reported. ${ }^{1,8}$ Cystoid macular edema, intraretinal/subretinal hemorrhages, retinal exudation, and neovascularization may be less commonly seen during the early stage of the disease. In late stage, the patients may present with severe vision loss. Clinically, the patients may have vitritis, narrowing of the retinal vessels, optic disc swelling/atrophy, diffuse/ focal depigmentation of RPE, multiple RPE track lesions leading to gray-white lesions. These evanescent, multifocal subretinal lesions are present at the level of the outer retina ${ }^{4,9}$ and are believed to be the area where the worm is present. These lesions characteristically migrate and change along with the worm and may or may not leave a residual retinal lesion depending on degree of host immune response against the toxic products of the worm. ${ }^{4}$

DUSN often poses a diagnostic challenge. A retrospective analysis of case series from two tertiary care centers of LV Prasad Eye Institute, India was conducted. The spectrum of clinical features, management, and outcomes were reviewed.

\section{Methods}

This was a retrospective analysis of medical records of patients diagnosed with DUSN between January 2011 and April 2014 in the two campuses of LV Prasad Eye Institute (Vijayawada and Visakhapatnam), India. The study was approved by the Institutional Review Board of LV Prasad Eye Institute, India. After informed and signed consent was obtained from the patients or legal guardians (in the case of minors), all subjects underwent detailed comprehensive eye examination. The study was performed in accordance with ethical principles as per the Declaration of Helsinki. Records of the patients presenting with anterior segment inflammation, vitritis, vasculitis, multifocal-migrating yellow-white subretinal lesions, diffuse and focal RPE damage, optic nerve atrophy, retinal vessel narrowing, and white subretinal track lesions suggestive of DUSN were included in the study. In the absence of identification of worm, the diagnosis of presumed DUSN was made on the bases of clinical features and exclusion of any other ocular disease. Patient data including age at presentation, sex, best-corrected Snellen visual acuity at presentation and last visit, presence of relative afferent pupillary defect, anterior segment inflammation, posterior segment findings (using 3-mirror Goldmann lens or 78 D lens), and central macular thickness (CMT) on optical coherence tomography (OCT) were recorded. Mean follow-up was 8.69 months (range, 1-21 months).

\section{Results}

A total of 13 patients ( 5 from Vijayawada and 8 from Visakhapatnam) were included in the study. Table 1 provides the detailed summary of these patients. Mean age at presentation was 22.5 years (range, 8-62 years). Most patients $(10 / 13,76.92 \%)$ were $\leq 20$ years at the time of presentation (Table 2). No predominant predilection for either sex was observed (male to female, 8:5). The patients were symptomatic before presentation for a period ranging from 1 day to 1 year. All patients presented with blurred vision in the affected eye. Visual acuity at presentation was $20 / 200$ or worse in 9/13 $(69.23 \%$ ) patients (Table 3). All patients had unilateral presentation, and relative afferent papillary defect was observed in 10/13 cases. Mild anterior segment inflammation was seen in only two cases (patient 2 and 4). Vitreous cells were present in all of the patients (vitreous cell in nine patients were $1+$ and in the remaining four patients $2+$ as per Standardization Uveitis Nomenclature SUN classification). Seven patients $(53.85 \%)$ presented in the early stage, while six patients $(46.15 \%)$ presented in the late stage of the disease. The posterior segment findings included vitritis, vasculitis, multifocal-migrating yellowwhite subretinal lesions (Figure 1), diffuse and focal RPE damage, optic nerve atrophy, retinal vessel narrowing, and white subretinal track lesions. Table 4 shows the frequency of the various clinical features at the time of presentation in this case series. RPE changes (13/13, 100\%), focal narrowing of vessels $(13 / 13,100 \%)$, and optic disc pallor $(7 / 13$, $57.14 \%$ ) were the most frequent findings. A worm could not be identified in any of these patients. All the patients received oral, high-dose antihelminthic (albendazole 400 $\mathrm{mg}$ or $15 \mathrm{mg} / \mathrm{kg}$ body weight, once daily) treatment for a period of 30 days. Laser photocoagulation was done either in the vicinity of the subretinal lesion or at the inferior peripheral retina in order to alter the blood-retina barrier and possibly allow increasing ocular penetration of albendazole. Improvement in visual acuity was noted as early as 1 week and stabilized by 1 month in all patients. Visual acuity improved in seven patients (six patients who presented during early stage and one patient who presented during late stage) and remained stable in six patients. During the late stage, the mean central foveal thickness in the affected eye was $188.20 \pm 40 \mu \mathrm{m}$ (range, 111-242 $\mu \mathrm{m}$ ), while in the other eye it was $238.70 \pm 36.90 \mu \mathrm{m}$ (range, 186-319 $\mu \mathrm{m})$. 


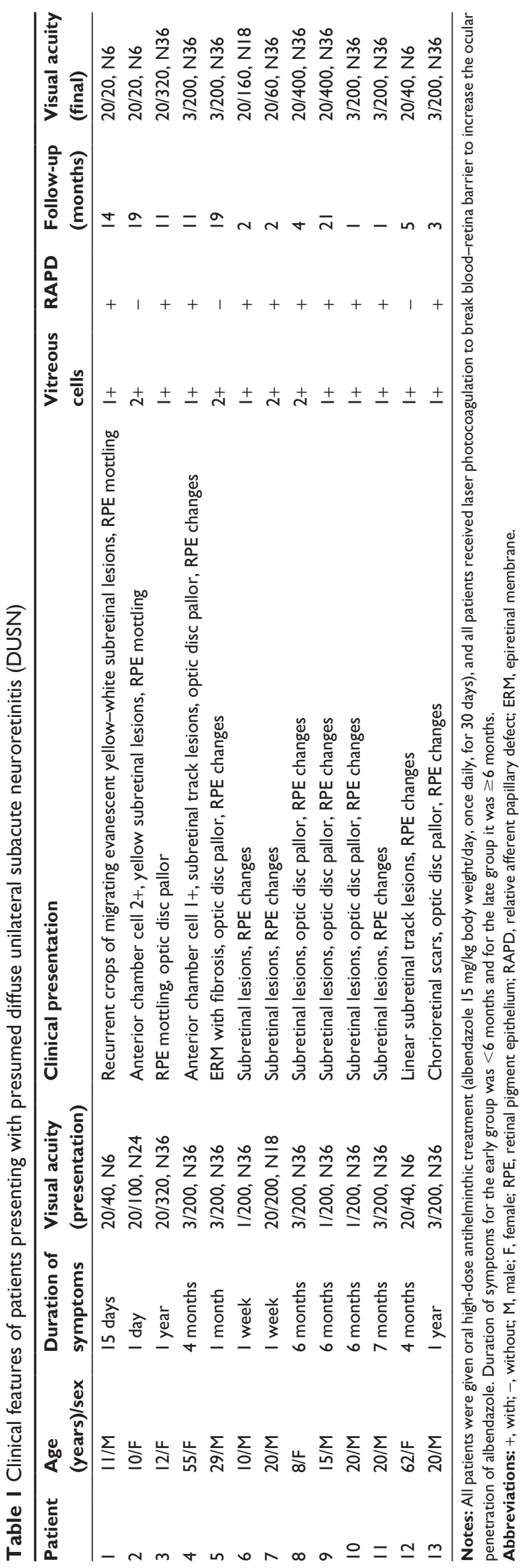

Table 2 Age distribution of patients with DUSN

\begin{tabular}{ll}
\hline Age at presentation & Number of patients \\
\hline$\leq 20$ years & $10(76.92 \%)$ \\
$>20$ years & $3(23.07 \%)$
\end{tabular}

Abbreviation: DUSN, diffuse unilateral subacute neuroretinitis.

\section{Discussion}

The current study included patients with presumed DUSN, where worm could not be identified and the diagnosis was based on the clinical findings. As per literature, the worm is visible in $33.3 \%-40.2 \%{ }^{10,11}$ of cases. The light sensitivity of the worm (on light exposure, the worm moves deeper and hides subretinally) and difficult peripheral retinal examination are the main hurdles in identifying subretinal worm. ${ }^{9}, 12$ Entry of the worm inside the eye occurs when nematode eggs, after being ingested, find their way to eye hematogenously, ${ }^{13}$ and then, for months to years the worm can wander in the subretinal space. DUSN was first thought to be caused by Toxocara, but later on, it was found to be caused by other species of nematodes as well, like Ancylostoma caninum, Baylisascaris procyonis, Strongyloides sp, Alaria mesocercaria, and filarial worms. ${ }^{14}$ The causative nematodes are of two types based on their length - small and large. The smaller nematodes (length range, 400-1,000 $\mu \mathrm{m}$ in length, with diameter being approximately $1 / 20$ th of its length; more common) include Ancylostoma caninum and Toxocara canis; endemic in Southeastern United States, the Caribbean, Venezuela, Brazil, and northern parts of South America. ${ }^{3,15,16}$ The larger nematodes - Baylisascaris procyonis (length range, 1,000-2,000 $\mu \mathrm{m}$ ) - are found in Northern midwestern United States, Europe, and Brazil., 3,16,17 DUSN is usually unilateral, though a few bilateral cases have been reported in literature. ${ }^{2,11,18}$ In the current study, all patients had unilateral presentation. Majority (69.42\%) of the patients in a retrospective case series of 121 Brazilian patients with DUSN ${ }^{12}$ were younger than 20 years, which is similar to the number of young patients in this case series $(76.92 \%$ - age 20 or less). Approximately $92 \%$ patients in Brazil study ${ }^{12}$ presented at late stage of the disease; however, in this case series, $53.85 \%$ patients (seven patients) presented in early stage. The exact pathogenesis of clinical findings seen in DUSN remain unclear, although the toxic inflammation due

Table 3 Visual acuity at presentation

\begin{tabular}{ll}
\hline Visual acuity & Number of patients \\
\hline Better than or equal to 20/40 & $2(15.38 \%)$ \\
$20 / 40$ to $20 / 200$ & $2(15.38 \%)$ \\
Worse than $20 / 200$ & $9(69.23 \%)$ \\
\hline
\end{tabular}



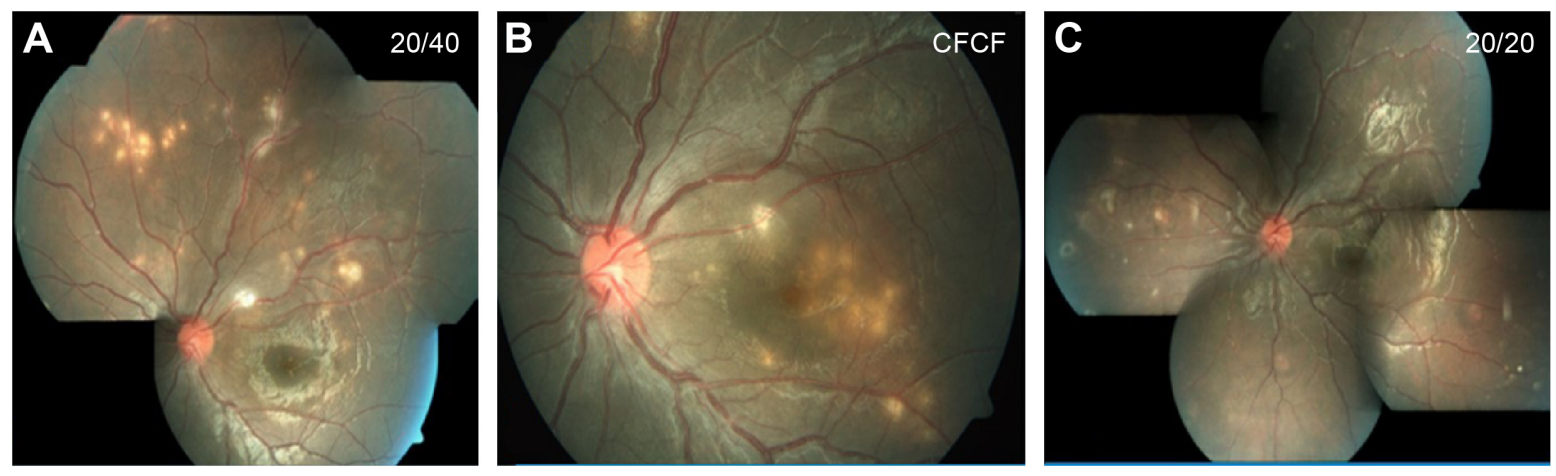

Figure I Fundus pictures of the left eye of an II-year-old child who presented with blurred vision.

Notes: (A) At presentation, multiple subretinal yellow-white lesions were seen superiorly and at the superotemporal periphery and treated with antitubercular drugs and oral steroids (tapered over 2 months). (B) I month after stopping oral steroids, recurrent crops of multiple yellow-white subretinal lesions appeared at macula, which were treated with laser photocoagulation to the inferior retina and high-dose oral albendazole therapy. (C) Complete resolution of lesions was observed at 2 months. The child remains recurrence free 2 years after treatment.

Abbreviations: $20 / 20$, Snellen visual acuity equivalent to $20 / 20$; CFCF, visual acuity counting fingers close to face; $20 / 40$, Snellen visual acuity equivalent to $20 / 40$.

to larval products and immune response of host to the toxin are believed to damage the inner as well as the outer retina, hence affecting retinal nerve fiber layer (RNFL), optic nerve, and RPE, anatomically and functionally. 1,4,5,19,20

Patients, who present during the early stage of the disease, are more likely to get improvement in visual acuity with treatment ${ }^{12,21,22}$ as compared to patients presenting during later stage of the disease. This pattern of response was observed in this study as well. Few uncommon, unusual presentations have been reported like the presence of multiple worms or macular cyst or worm at macula. ${ }^{23-25}$ Treatment of choice is the destruction of worm with laser photocoagulation (using $500 \mu \mathrm{m}, 0.5$-second argon laser applications) whenever it was visible. ${ }^{4,16}$ The worm is usually found in the vicinity of yellow-white retinal lesions. ${ }^{16}$ Less than $1 \%$ of the lesions (which are supposed to be the clue to the presence of worm) are of sufficient clarity to be identified clinically, and therefore it may not be possible to find a worm in all patients. In cases where worm cannot be identified despite careful and intensive time consuming eye examination, high-dose oral antihelminthic therapy (albendazole $400 \mathrm{mg} / \mathrm{d}$ or $15 \mathrm{mg} / \mathrm{kg}$ body weight, once daily for 30 days) is recommended (similar to the treatment of neurocysticercosis) along with application of laser photocoagulation adjacent to the yellow-white retinal lesion (or in periphery where no focal lesions are present). ${ }^{3,26}$ Albendazole is a broad-spectrum benzimidazole antihelminthic developed approximately 35 years ago. ${ }^{27}$ It binds to $\beta$-tubulin of parasites and inhibits its polymerization and impairs glucose uptake. High-dose oral albendazole therapy has been reported to be effective. ${ }^{10}$ Ocular penetration of albendazole is supposed to increase by disrupting blood-retina barrier by laser photocoagulation, ${ }^{28,29}$ as was done for all patients in this case series. Posttreatment recovery of visual fields has been reported, ${ }^{10,21,22}$ and in the current study, visual acuity improved in 7/13 (53.85\%) cases.

DUSN resembles few other ocular diseases that are difficult to diagnose. In early stage of the disease, it may

Table 4 Posterior segment findings in patients with presumed DUSN

\begin{tabular}{llll}
\hline Clinical finding & $\begin{array}{l}\text { Number of patients, } \\
\text { (both groups) } \mathbf{n}(\%) \mathbf{( N = 1 3 )}\end{array}$ & $\begin{array}{l}\text { Number of patients - } \\
\text { early group (N=7), } \mathbf{n} / \mathbf{N}^{*}\end{array}$ & $\begin{array}{l}\text { Number of patients - } \\
\text { late group (N=6), } \mathbf{n} / \mathbf{N} *\end{array}$ \\
\hline Focal RPE alterations & $13(100 \%)$ & $7 / 7$ & $6 / 6$ \\
Vitritis & $13(100 \%)$ & $7 / 7$ & $6 / 6$ \\
Narrowing of retinal vessels & $13(100 \%)$ & $7 / 7$ & $6 / 6$ \\
Optic disc pallor & $7(53.85 \%)$ & $2 / 7$ & $5 / 6$ \\
Yellow-white subretinal lesions & $7(53.85 \%)$ & $3 / 7$ & $4 / 6$ \\
Subretinal track lesions & $2(15.38 \%)$ & $2 / 7$ & $0 / 6$ \\
Vasculitis & $3(23.07 \%)$ & $3 / 7$ & $0 / 6$ \\
Fibrosis over disc & $2(15.38 \%)$ & $2 / 7$ & $0 / 6$ \\
Retinal edema & $\mathrm{Nil}$ & $\mathrm{Nil}$ & $\mathrm{Nil}$ \\
Live worm & $\mathrm{Nil}$ & $\mathrm{Nil}$ & $\mathrm{Nil}$ \\
\hline
\end{tabular}

Notes: Duration of symptoms for the early group was $<6$ months and for the late group it was $\geq 6$ months. ${ }^{n}$ is the number of patients with the finding, and $\mathrm{N}$ is the total number of patients in the group.

Abbreviations: DUSN, diffuse unilateral subacute neuroretinitis; RPE, retinal pigment epithelium. 
resemble conditions such as retinal sarcoidosis, acute multifocal posterior placoid pigment epitheliopathy, serpiginous choroiditis, multiple evanescent white dot syndrome, Behçet's disease, multifocal toxoplasmosis, and presumed ocular histoplasmosis syndrome. In the later stage, the disease may mimic unilateral optic atrophy caused by retrobulbar or intracranial lesions, the presumed ocular histoplasmosis syndrome, unilateral retinitis pigmentosa, posttraumatic chorioretinopathy, and chorioretinal atrophy after central retinal artery occlusion, syphilis, sarcoidosis etc. ${ }^{3,9}$ In this case series, 6/13 patients were initially diagnosed as having retinitis pigmentosa (4) and posterior uveitis (2), which delayed treatment. A detailed workup, including history (profound vision loss in one eye, photopsia) and ocular examination (optic atrophy, vascular attenuation, presence of normal looking RPE in between punched out lesions), are the initial steps toward making clinical diagnosis. The ancillary tests include fluorescein angiography (in active stage of DUSN, gray-white lesions are hypofluorescent in early phase of angiogram and stain in the later phase of angiogram along with disc leak, while in late stage of DUSN, irregular increase in background choroidal fluorescence is noted), ${ }^{3,16}$ electroretinography (subnormal waveforms with $\mathrm{b}$ waves affected more than a waves), ${ }^{3,30,31}$ multifocal electroretinography (decreased foveal response and increased parafoveal and perifoveal waveform amplitudes), ${ }^{31}$ indocyanine green angiography (dark spot in early phase of angiogram which disappears or persists in later phase of angiogram), ${ }^{32}$ and OCT (decreased RNFL and CMT) ${ }^{19}$ that may help in assessing the stage of the disease. In this case series, the CMT of patients in late stage showed thinning compared to the other eye. In a case series of eight patients from Brazil, Garcia Filho et $\mathrm{al}^{19}$ found that RNFL and CMT were thinner in DUSN eyes compared to the normal eyes, and this thinning was more prominent in the late stage of the disease. Figure 2 shows increased CMT during active stage $(=315 \mu \mathrm{m})$ and gradual decrease in CMT during late stage of the disease $(257 \mu \mathrm{m})$, which was seen during follow-up of a patient from this case series. Other OCT abnormalities such as loss of foveal depression and focal/diffuse defects at the ellipsoid zone (inner segment/outer segment junction) have also been mentioned in DUSN patients. ${ }^{19}$ Other tests such as visual field, serological studies, stool examination, and peripheral blood smears are of limited value in making the diagnosis of DUSN. ${ }^{1}$ Gass et $\mathrm{al}^{1}$ mentions that patients may have choroidal neovascular membrane (CNVM) or disciform scar in later stage of the disease. A poster presentation at ARVO (Association for Research in Vision and Ophthalmology) in 2011 by Shah et $\mathrm{al}^{33}$ from Bascom Palmer Eye Institute, (three cases) mentioned that atrophic changes of macula precede the onset of type 2 CNVM; however, in the current study, CNVM was
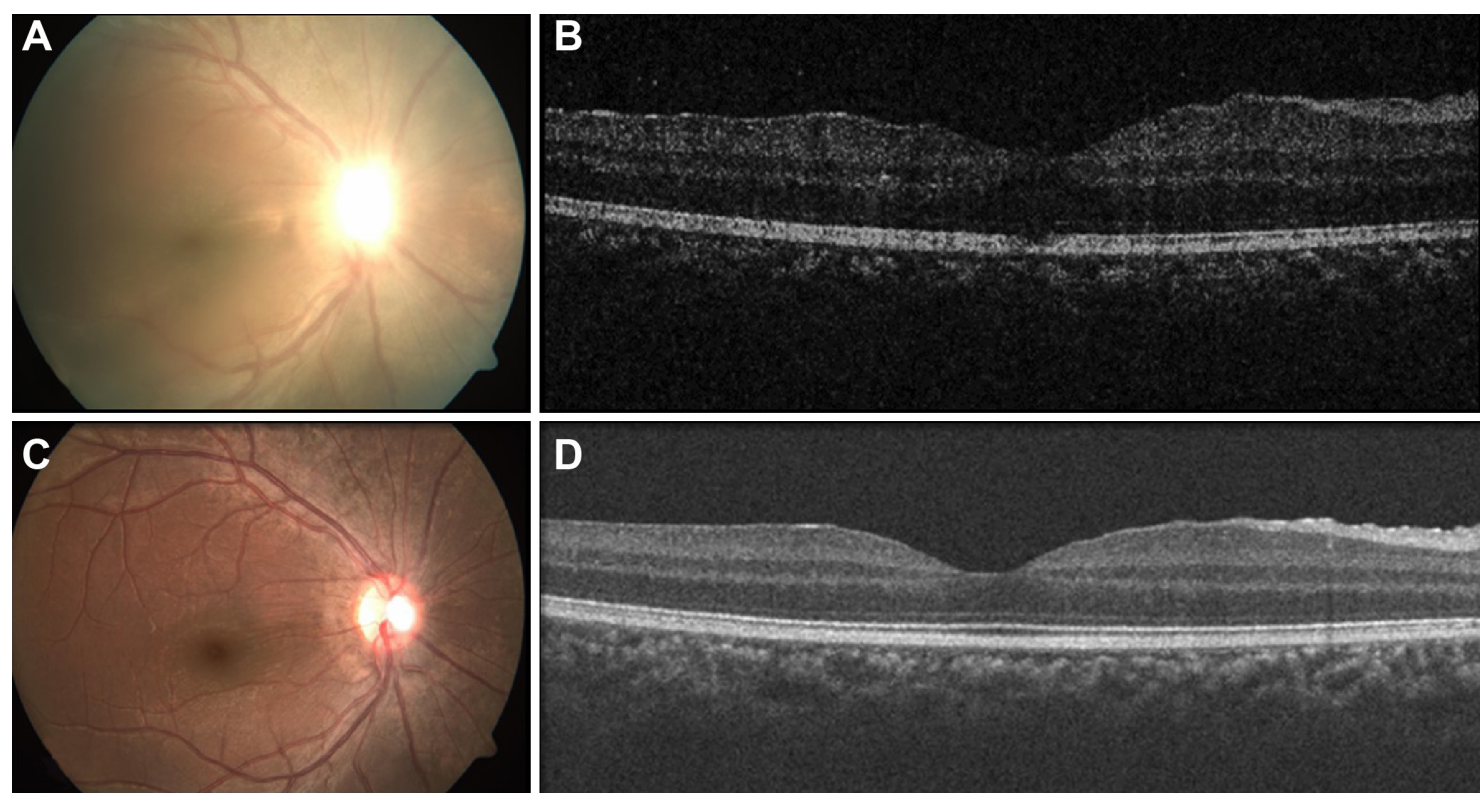

Figure 2 Fundus pictures and OCT images of early stage and chronic stage of the disease.

Notes: Fundus picture (A) and OCT (B) of right eye of a patient in the early stage of the disease showing hazy view due to vitritis, blurred disc margin, loss of foveal reflex, and macular thickening (central macular thickness $=315 \mu \mathrm{m}$ ). Fundus picture $(\mathbf{C})$ and OCT $(\mathbf{D})$ of the same eye in the chronic stage of the disease showing resolved vitreous haze, disc pallor, and decreased macular thickening (central macular thickness $=240 \mu \mathrm{m}$ ). OCT machine used was Cirrus $4000 \mathrm{SW}$ version: 5.2 .0 .210 , Carl Zeiss Meditec, Jena, Germany.

Abbreviation: OCT, optical coherence tomography. 
not noted in any of the patients. A longer follow-up to look for delayed changes is recommended.

In conclusion, DUSN is a vision threatening ocular infectious disease, which may progress to profound vision loss in the later stages of the disease. The presence of focal RPE alterations, vitreous inflammation, narrowing of retinal vessels, optic disc pallor, and yellow-white subretinal lesions are highly suggestive of DUSN. Detailed ophthalmoscopic examination and fundus photography are helpful in making a diagnosis. However, it is not possible to identify the subretinal worm in most cases. In such patients, high-dose albendazole therapy and laser photocoagulation may help in controlling the disease activity and may reduce further damage by the subretinal worm. The disease process may be reversible in the early stages as improvement in visual acuity in some patients has been observed with treatment.

\section{Acknowledgment}

We gratefully acknowledge Rajawardhan Mallipudi and Podili Srinivas Rao for collection of data and photographic support. Both are working as faculty optometrists at LV Prasad Eye Institute, Vijayawada, India.

\section{Disclosure}

The authors declare that they have no competing interests (financial or nonfinancial).

\section{References}

1. Gass JD, Gilbert WR Jr, Guerry RK, Scelfo R. Diffuse unilateral subacute neuroretinitis. Ophthalmology. 1978;85(5):521-545.

2. Wilder HC. Nematode endophthalmitis. Trans Am Acad Ophthalmol Otolaryngol. 1950;55:99-109.

3. Gass JDM. Stereoscopic atlas of macular diseases: diagnosis and treatment. 4th ed. St Louis, MO: Mosby; 1997.

4. Gass JD, Braunstein RA. Further observations concerning the diffuse unilateral subacute neuroretinitis syndrome. Arch Ophthalmol. 1983; 101(11):1689-1697.

5. Gass JD, Scelfo R. Diffuse unilateral subacute neuroretinitis. J R Soc Med. 1978;71(2):95-111.

6. Carney MD, Combs JL. Diffuse unilateral subacute neuroretinitis. Br J Ophthalmol. 1991;75(10):633-635.

7. Audo I, Webster AR, Bird AC, Holder GE, Kidd MN. Progressive retinal dysfunction in diffuse unilateral subacute neuroretinitis. $\mathrm{Br} J$ Ophthalmol. 2006;90(6):793-794.

8. Muccioli C, Belfort R Jr. Hypopyon in a patient with presumptive diffuse unilateral subacute neuroretinitis. Ocul Immunol Inflamm. 2000; 8(2):119-121.

9. Cortez RT, Ramirez G, Collet L, Giuliari GP. Ocular parasitic diseases: a review on toxocariasis and diffuse unilateral subacute neuroretinitis. J Pediatr Ophthalmol Strabismus. 2011;48(4):204-212.

10. Souza EC, Casella AM, Nakashima Y, Monteiro ML. Clinical features and outcomes of patients with diffuse unilateral subacute neuroretinitis treated with oral albendazole. Am J Ophthalmol. 2005;140(3): $437-445$.
11. Cortez R, Denny JP, Muci-Mendoza R, Ramirez G, Fuenmayor D, Jaffe GJ. Diffuse unilateral subacute neuroretinitis in Venezuela. Ophthalmology. 2005;112(12):2110-2114.

12. de Amorim Garcia Filho CA, Gomes AH, de A Garcia Soares AC, de Amorim Garcia CA. Clinical features of 121 patients with diffuse unilateral subacute neuroretinitis. Am J Ophthalmol. 2012;153(4):743-749.

13. Holland GN, Pepose JS, Wilhelmus KR. Ocular infection and immunity. St Louis, MO: Mosby; 1996.

14. Albert DM, Jakobiec FA. Principles and practice of ophthalmology. 2nd ed. Philadelphia, PA: W.B. Saunders Co; 2000.

15. de Souza EC, da Cunha SL, Gass JD. Diffuse unilateral subacute neuroretinitis in South America. Arch Ophthalmol. 1992;110(9):1261-1263.

16. Ryan SJ. Retina. 3rd ed. St Louis, MO: Mosby; 2001.

17. Goldberg MA, Kazacos KR, Boyce WM, Ai E, Katz B. Diffuse unilateral subacute neuroretinitis. Morphometric, serologic, and epidemiologic support for Baylisascaris as a causative agent. Ophthalmology. 1993; 100(11):1695-1701.

18. de Souza EC, Abujamra S, Nakashima Y, Gass JD. Diffuse bilateral subacute neuroretinitis: first patient with documented nematodes in both eyes. Arch Ophthalmol. 1999;117(10):1349-1351.

19. Garcia Filho CA, Soares AC, Penha FM, Garcia CA. Spectral domain optical coherence tomography in diffuse unilateral subacute neuroretinitis. J Ophthalmol. 2011;2011:285296.

20. John T, Barsky HJ, Donnelly JJ, Rockey JH. Retinal pigment epitheliopathy and neuroretinal degeneration in ascarid-infected eyes. Invest Ophthalmol Vis Sci. 1987;28(9):1583-1598.

21. Garcia CA, Gomes AH, Garcia Filho CA, Vianna RN. Early-stage diffuse unilateral subacute neuroretinitis: improvement of vision after photocoagulation of the worm. Eye (Lond). 2004;18(6):624-627.

22. Garcia CA, Gomes AH, Vianna RN, Souza Filho JP, Garcia Filho CA, Orefice F. Late-stage diffuse unilateral subacute neuroretinitis: photocoagulation of the worm does not improve the visual acuity of affected patients. Int Ophthalmol. 2005;26(1-2):39-42.

23. Harto MA, Rodriguez-Salvador V, Avino JA, Duch-Samper AM, Menezo JL. Diffuse unilateral subacute neuroretinitis in Europe. Eur J Ophthalmol. 1999;9(1):58-62.

24. Vedantham V, Vats MM, Kakade SJ, Ramasamy K. Diffuse unilateral subacute neuroretinitis with unusual findings. Am J Ophthalmol. 2006; 142(5):880-883.

25. Yusoff M, Alwi AA, Said MM, Zakariah S, Ghani ZA, Zunaina E. Intraocular nematode with diffuse unilateral subacute neuroretinitis: case report. BMC Ophthalmol. 2011;11:15.

26. Gass JD, Callanan DG, Bowman CB. Oral therapy in diffuse unilateral subacute neuroretinitis. Arch Ophthalmol. 1992;110(5):675-680.

27. Venkatesan P. Albendazole. J Antimicrob Chemother. 1998;41(2): 145-147.

28. Maguire AM, Zarbin MA, Connor TB, Justin J. Ocular penetration of thiabendazole. Arch Ophthalmol. 1990;108(12):1675.

29. Gass JD, Callanan DG, Bowman CB. Successful oral therapy for diffuse unilateral subacute neuroretinitis. Trans Am Ophthalmol Soc. 1991;89: 97-112; discussion 113-116.

30. Kelsey JH. Diffuse unilateral subacute neuroretinitis. J R Soc Med. 1978; 71(4):303-304.

31. Sabrosa NA, de Souza EC. Nematode infections of the eye: toxocariasis and diffuse unilateral subacute neuroretinitis. Curr Opin Ophthalmol. 2001;12(6):450-454.

32. Arevalo JF, Arevalo FA, Garcia RA, de Amorim GFC, de Amorim GC. Diffuse unilateral subacute neuroretinitis. J Pediatr Ophthalmol Strabismus. 2013;50(4):204-212.

33. Shah M, Jacobs DJ, Berrocal AM. Spectral domain OCT findings in Diffuse Acute Unilateral Neuroretinitis (DUSN) with subretinal neovascularization. Invest Ophthalmol Vis Sci. 2011;52:E-abstract 2172. 


\section{Publish your work in this journal}

Clinical Ophthalmology is an international, peer-reviewed journal covering all subspecialties within ophthalmology. Key topics include: Optometry; Visual science; Pharmacology and drug therapy in eye diseases; Basic Sciences; Primary and Secondary eye care; Patien Safety and Quality of Care Improvements. This journal is indexed on Submit your manuscript here: http://www.dovepress.com/clinical-ophthalmology-journal
Dovepress

PubMed Central and CAS, and is the official journal of The Society of Clinical Ophthalmology (SCO). The manuscript management system is completely online and includes a very quick and fair peer-review system, which is all easy to use. Visit http://www.dovepress.com/ testimonials.php to read real quotes from published authors. 